\title{
Increase in Tuberculosis Cases among Prisoners, Brazil, 2009-2014 ${ }^{1}$
}

\author{
Paul M. Bourdillon, Crhistinne C.M. Gonçalves, \\ Daniele Maria Pelissari, Denise Arakaki-Sanchez, \\ Albert I. Ko, Julio Croda, Jason R. Andrews
}

During 2009-2014, incarceration rates in Brazil rose 34\%, and tuberculosis (TB) cases among prisoners rose $28.8 \%$. The proportion of national TB cases that occurred among prisoners increased from $6.2 \%$ to $8.4 \%$ overall and from $19.3 \%$ to $25.6 \%$ among men $20-29$ years of age.

$\mathrm{I}_{\mathrm{r}}^{\mathrm{n}}$ 2014, Brazil had the world's fourth largest prison population, with more than half a million prisoners in 1,424 facilities (1). Prison conditions include overcrowding, frequent prisoner movement, poor ventilation, and limited access to diagnostic facilities; these conditions favor tuberculosis (TB) transmission (2-5). Many key factors for progression from TB infection (determined by positive test results) to disease (determined by clinical diagnostic criteria) also are common; these include alcohol and drug abuse, tobacco smoking, undernutrition, and HIV prevalence (6). Although surveys have reported high rates of TB among prisoners in Brazil (6-9), state-level and temporal trends in TB notifications and the contribution of the epidemic in prisons to the overall TB case burden have not been evaluated. To estimate trends in TB cases among prisoners and to identify incarcerated populations at high risk for infection, we analyzed data from the national disease notification database, census data, and administrative data.

\section{The Study}

We obtained individual-level data on TB cases reported during 2007-2014 in the Brazil national notification database (Sistema de Informação de Agravos de Notificação; SINAN). A new form for SINAN was introduced in 2007, which led to an increase in documentation of incarceration status from $68 \%$ in 2007 to $94 \%$ in 2009 . Our analysis therefore focuses on data from 2009-2014, when documentation

Author affiliations: Yale University, New Haven, Connecticut, USA (P.M. Bourdillon, A.I. Ko); Federal University of Grande Dourados, Dourados, Brazil (C.C.M. Gonçalves, J. Croda); University of São Paulo, São Paulo, Brazil (D.M. Pelissari); Ministry of Health of Brazil, Brasília, Brazil (D.M. Pelissari, D. Arakaki-Sanchez); Oswaldo Cruz Foundation, Campo Grande and Salvador, Brazil (J Croda, A.I. Ko); Stanford University, Stanford, California, USA (J.R. Andrews)

DOI: http://dx.doi.org/10.3201/eid2303.161006 rates were consistently $\geq 92 \%$. We extracted demographic data on incarceration status, sex, age, and state as well as clinical presentation, HIV status, and sputum smear positivity. This work was approved by the human research protection program at Yale University and the institutional review board at the Federal University of Grande Dourados.

Among prisoners, TB case-patients were defined as persons for whom TB was notified while they were incarcerated, including those in penal institutions awaiting trial or sentencing. To calculate annual TB notification rates (cases per 100,000 persons), we used population estimates for Brazil from the 2010 Census and projections and midyear incarcerated population data from the Ministry of Justice. To compare TB notification rates between incarcerated and nonincarcerated populations, aggregated at the state level, we used the Pearson product-moment correlation.

During 2009-2014, a total of $38,327(7.3 \%)$ of the 526,569 cases of TB reported in Brazil occurred in prisoners. The total number of cases reported in prisoners increased $28.8 \%$, from 5,556 to 7,157 per year, and the proportion of cases notified among prisoners increased from $6.2 \%$ in 2009 to $8.4 \%$ in 2014. During the same period, the prison population grew from 409,287 to 579,781 , an increase of $41.7 \%$, as overall incarceration rates rose $33.9 \%$, from 214 to $287 / 100,000$ persons. Because of that increase, the rate of TB notifications dropped from 1,357 to $1,234 / 100,000$ for prisoners $(9.1 \%$ decrease); meanwhile, the rate of TB notifications for nonprisoners dropped $12.2 \%$ (from 43.7 to $38.4 / 100,000$ persons). Overall, the mean annual notification rate among prisoners was 31.3 times that of the general population (Table).

HIV status was known for $66 \%$ of all TB patients; prevalence was $15.9 \%$ among prisoners and $17.4 \%$ among nonprisoners (Table). Notification rates varied substantially among states. Average annual 2009-2014 notification rates among prisoners ranged from 225 (Rondônia) to 2,548 (Rio de Janeiro). At the state level, 2014 notification rates were positively correlated (Pearson $\rho 0.54 ; p=0.002$ ) between the nonincarcerated population and prisoners.

Men comprised $93.8 \%$ of the prison population and accounted for $91.9 \%$ of prison TB cases; $74.7 \%$ were $18-39$ years of age, compared with only $39.8 \%$ in this age range among nonprisoners with TB. In 2014, a total of $25.6 \%$ of all men 20-29 years of age were prisoners (state range for

${ }^{1}$ Preliminary results from this study were presented at the 46th Union World Conference on Lung Health, December 2-6, 2016, Cape Town, South Africa. 
Table. Annual average data for tuberculosis notifications, by incarceration status and gender, Brazil, 2009-2014

\begin{tabular}{|c|c|c|c|c|c|c|c|}
\hline \multirow[b]{2}{*}{ Category } & \multicolumn{3}{|c|}{ General population } & \multicolumn{3}{|c|}{ Prisoners } & \multirow{2}{*}{$\begin{array}{l}\text { p value, men } \\
\text { vs. women* }\end{array}$} \\
\hline & All & Men & Women & All & Men & Women & \\
\hline Population, thousands & 194,898 & 96,546 & 98,352 & 490 & 459 & 31 & $<0.0001$ \\
\hline Annual no. cases & 81,370 & 53,138 & 28,227 & 6,388 & 5,869 & 519 & $<0.0001$ \\
\hline $\begin{array}{l}\text { Notification rate, cases } / 100,000 \\
\text { population }\end{array}$ & 42 & 55 & 29 & 1,307 & 1,281 & 1,703 & 0.001 \\
\hline HIV status reported, \%† & 66.1 & 66.6 & 65.3 & 65.9 & 65.9 & 66.0 & 0.97 \\
\hline HIV co-infection, \%‡ & 17.4 & 18.2 & 15.8 & 15.9 & 15.2 & 24.1 & 0.003 \\
\hline Smear positive, \% & 55.5 & 57.2 & 52.2 & 65.5 & 66.4 & 55.2 & $<0.0001$ \\
\hline Extrapulmonary, \% & 17.5 & 16.4 & 19.5 & 8.2 & 7.4 & 16.7 & 0.0002 \\
\hline Treatment success, $\%$ & 66.6 & 64.4 & 70.9 & 69.5 & 69.8 & 66.0 & 0.09 \\
\hline
\end{tabular}

${ }^{*} \mathrm{p}$ values calculated with the Welch $t$-test comparing prisoners' annual data by sex.

†HIV status based on a positive or negative status result or AIDS diagnosis from the time of tuberculosis notification.

$\ddagger \%$ HIV co-infection calculated as percentage positive HIV+ results among those with HIV status reported.

all prisoners $0 \%-47.8 \%$; Figure 1, panels A, B). Although there were far fewer female prisoners, incarceration rates rose faster for women $(50.0 \%$ vs. $30.2 \%$; Figure 2$)$, and the average annual TB notification rate was higher for female prisoners than for male prisoners (1,703 vs. 1,281; Figure 2 ). The prevalence of extrapulmonary disease among women was twice that in men $(16.7 \%$ vs. $7.4 \% ; p=0.0002)$. HIV co-infection rates were also higher for female prisoners $(24.1 \%$ vs. $15.2 \% ; \mathrm{p}=0.003$, Table).

\section{Conclusions}

Prisoners have been recognized as a group at high risk for TB, but there has been limited assessment of the contribution of recent increases in TB prevalence in the prison population to the overall TB case burden in Brazil. We combined data from a national TB notification database with incarceration data and found that prisons account for a growing proportion of the national TB burden in Brazil. In 2014, a total of 8.4\% of all reported cases occurred among prisoners, who represent $<0.3 \%$ of the population, representing a $35.4 \%$ increase in the proportion of TB cases occurring among prisoners in 5 years. Among young men 20-29 years of age, a growing proportion $(>25 \%)$ of TB cases occurred among those who were incarcerated. For the nonincarcerated population, TB notification rates fell by $12.2 \%$ during this period; however, when prisoners were included in assessments, $16.8 \%$ of

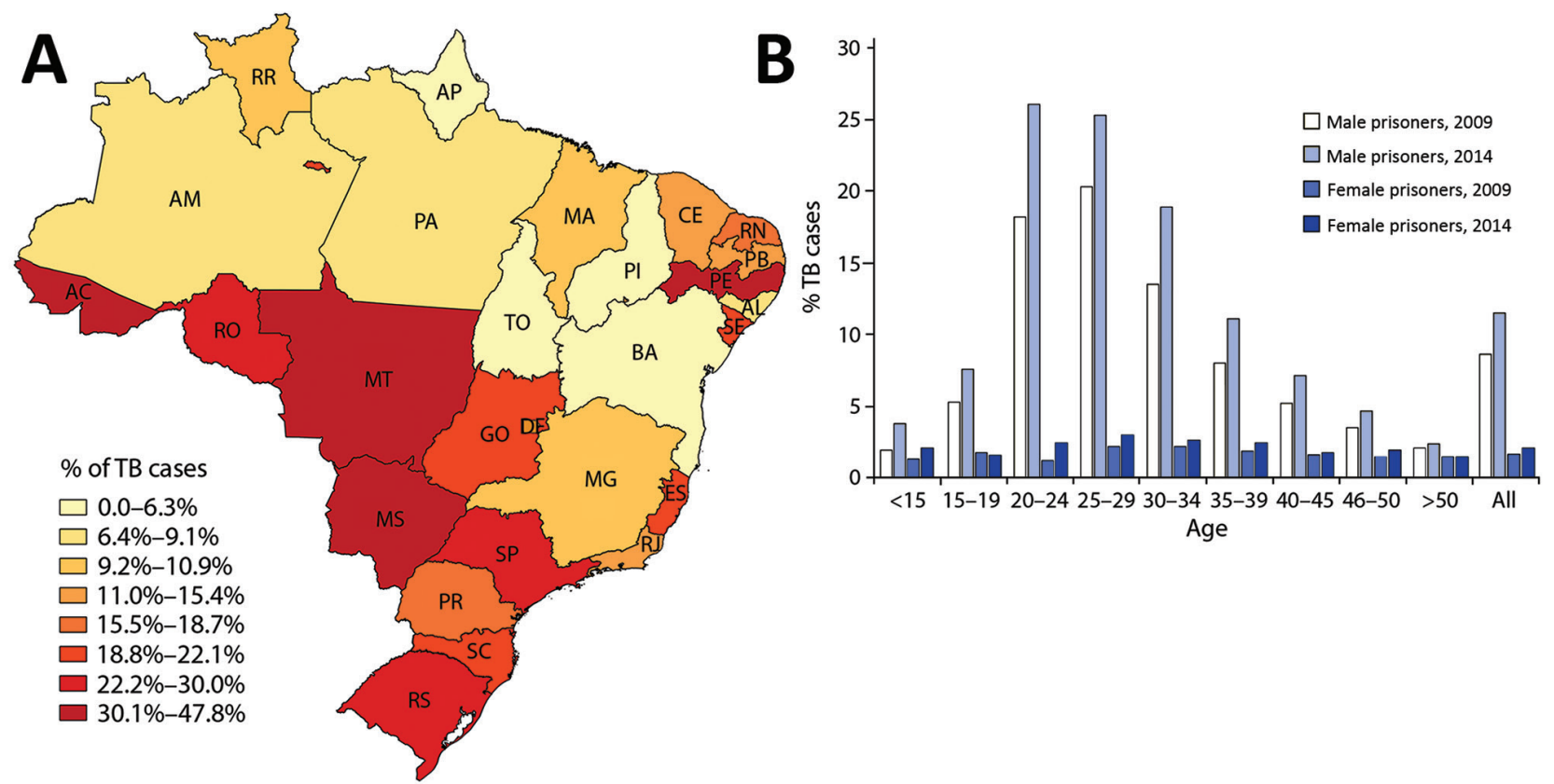

Figure 1. Proportion of tuberculosis (TB) cases among prisoners in Brazil, 2009-2014. A) Geographic distribution by state of the proportions of all TB cases diagnosed among male prisoners ages 20-29. Prisoners comprised $0-47.7 \%$ of all TB cases in this age group, with highest rates at the western border of Brazil. B) Sex and age distribution of the proportions of all notified TB cases diagnosed among prisoners in Brazil for 2009 compared with 2014. Prisoners of both sexes represent an increasingly disproportionate percentage of notified cases in all age groups, and male prisoners 20-29 of age represented $>25 \%$ of cases among the age group in 2014. AC, Acre; AL, Alagoas; AP, Amapá; AM, Amazonas; BA, Bahia; CE, Ceará; DF, Distrito Federal; ES, Espírito Santo; GO, Goiás; MA, Maranhão; MT, Mato Grosso; MS, Mato Grosso do Sul; MG, Minas Gerais; PR, Paraná; PB, Paraíba; PA, Pará; PE, Pernambuco; PI, Piauí; RJ, Rio de Janeiro; RN, Rio Grande do Norte; RS, Rio Grande do Sul; RO, Rondônia; RR, Roraima; SC, Santa Catarina; SE, Sergipe; SP, São Paulo; TO, Tocantins. 


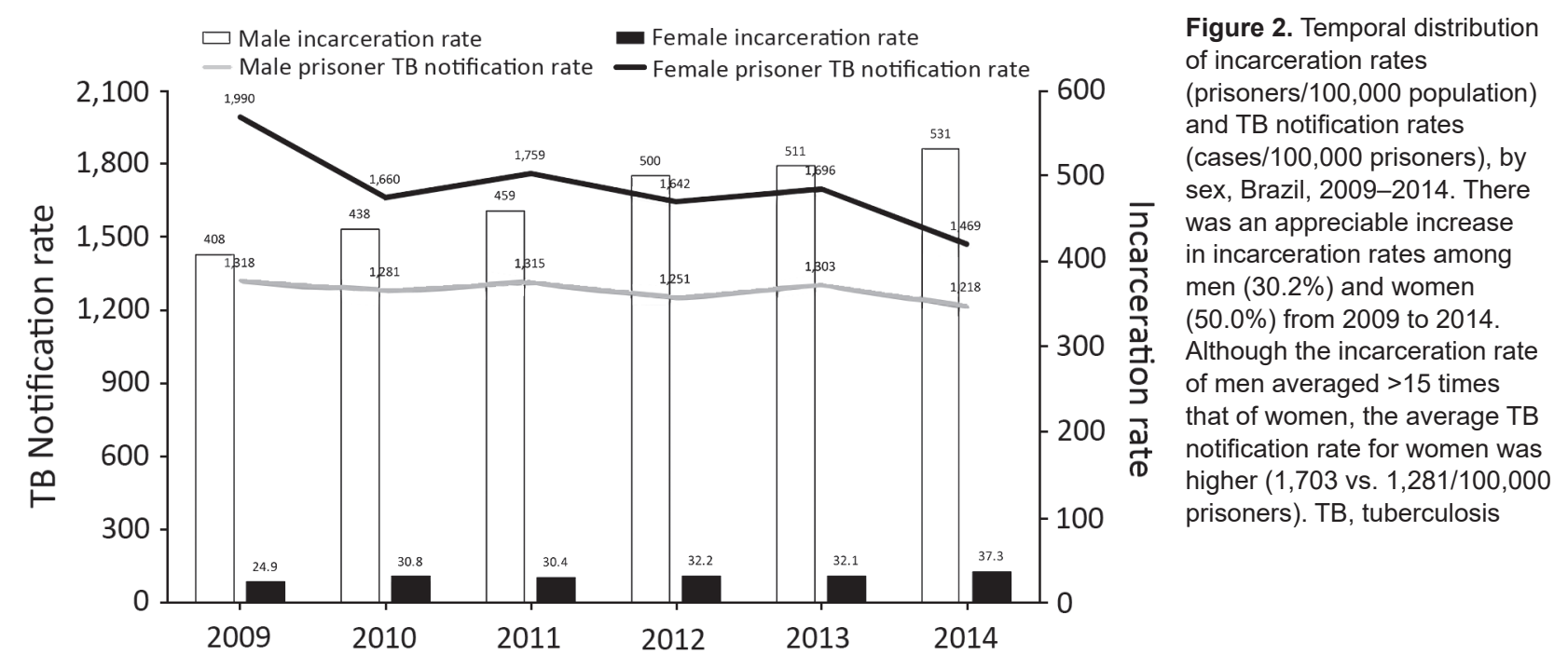

these gains were offset by increasing incarceration rates, as notification rates among prisoners were 31.3 times higher than those for the general population. Failure to address TB in an expanding incarcerated population may be a critical barrier to achieving national targets for TB control.

Our analysis also revealed that female prisoners are at higher risk for TB. Incarceration rates among women rose faster, and TB notification rates and HIV co-infection rates were higher than corresponding rates among men. This finding is in contrast to the overall global epidemiology of TB and to national data for the nonincarcerated population, which demonstrated higher TB notification rates among men than women (50.1 vs. $26.5 / 100,000$ persons; Table). A potential explanation is the higher rate of HIV-associated TB among female prisoners than among men ( $24.1 \%$ vs. $15.2 \%)$. We previously reported a higher prevalence of HIV among female prisoners in Brazil (10), as have others $(11,12)$. HIV alone is unlikely to explain the large disparities in TB rates between male and female prisoners; more data are needed to explain the inverted sex disparities (compared with the general population) in TB patients in prisons in Brazil.

This study had several limitations. First, we assessed notification rates at the national and state level; although we observed substantial heterogeneity at the state level, more data on prison characteristics and incarceration rates are needed to understand factors driving TB in prisons. In particular, the relative contribution of individual risk factors for TB reactivation and the effects of prison environments and policies on transmission are poorly understood. Second, our use of data from reported cases may include demographic or diagnostic misclassification. Third, we could not assess cases among recently released prisoners; many prisoners are released without sentencing or after serving sentences of $<5$ years (1), and infections acquired in prison may be diagnosed after prisoners are released. Consequently, the number of cases notified among prisoners (incarcerated at the time of diagnosis) probably underestimates the true effect of prisons on the population-level TB case burden.

Our findings demonstrate that the epidemic of TB in prisons represents a larger challenge to national TB control in Brazil than the threat posed to prisoners' health $(4,13)$. There is an urgent need to address notification rates in prisons in Brazil by using effective interventions such as active case detection, preventive therapy, and transitional care for released prisoners $(2,3,5,14)$. A recent study demonstrated high rates of nonadherence to treatment among prison prisoners in Brazil, underscoring the need to ensure that prisoners complete treatment to prevent transmission within and outside prisons (15). In addition to improving access to TB diagnosis and treatment within prisons, addressing rising incarceration rates and improving living condtions that favor transmission in prisons may be critical to combat TB among prisoners (16).

This project was supported by the Wilbur G. Downs Fellowship, the Yale School of Medicine Office of Student Research, the Global Health Equity Scholars Program (NIH 1R25 TW009338), and the Infectious Diseases Society of America Medical Scholars Program.

Mr. Bourdillon is a medical student at the Yale School of Medicine. His research focuses on TB control in marginalized populations.

\section{References}

1. Whately de Moura T, Natália CTR. Levantamento Nacional de Informações Penitenciárias Infopen-Junho de 2014. Brasíla (Brazil); Brazilian Ministry of Justice; 2015.

2. Galea G, Enggist S, Udesen C, Møller L. Prisons and Health. Copenhagen: WHO Regional Office for Europe; 2014.

3. Dara M, Grzemska M, Kimerling ME, Reyes H, Zagorskiy A. Guidelines for control of tuberculosis in prisons. Washington: US Agency for International Development; 2009.

4. Basu S, Stuckler D, McKee M. Addressing institutional amplifiers in the dynamics and control of tuberculosis epidemics. 
Am J Trop Med Hyg. 2011;84:30-7. http://dx.doi.org/10.4269/ ajtmh.2011.10-0472

5. Sánchez A, Huber FD, Massari V, Barreto A, Camacho LA, Cesconi V, et al. Extensive Mycobacterium tuberculosis circulation in a highly endemic prison and the need for urgent environmental interventions. Epidemiol Infect. 2012;140:1853-61. http://dx.doi.org/10.1017/S0950268811002536

6. Carbone AS, Paião DS, Sgarbi RV, Lemos EF, Cazanti RF, Ota MM, et al. Active and latent tuberculosis in Brazilian correctional facilities: a cross-sectional study. BMC Infect Dis. 2015;15:24. http://dx.doi.org/10.1186/s12879-015-0764-8

7. Nogueira PA, Abrahão RMCM, Galesi VMN. tuberculosis and latent tuberculosis in prison prisoners. Rev Saude Publica. 2012;46:11927. http://dx.doi.org/10.1590/S0034-89102011005000080

8. Estevan AO, Oliveira SM, Croda J. Active and latent tuberculosis in prisoners in the Central-West Region of Brazil. Rev Soc Bras Med Trop. 2013;46:515-8. http://dx.doi.org/10.1590/ 0037-8682-1441-2013

9. Sacchi FPC, Praça RM, Tatara MB, Simonsen V, Ferrazoli L, Croda MG, et al. Prisons as reservoir for community transmission of tuberculosis, Brazil. Emerg Infect Dis. 2015;21:452-5. http://dx.doi.org/10.3201/eid2103.140896

10. Sgarbi RVE, Carbone AS, Paião DSG, Lemos EF, Simionatto S, Puga MA, et al. A cross-sectional survey of hiv testing and prevalence in twelve brazilian correctional facilities. PLoS One. 2015;10:e0139487. http://dx.doi.org/10.1371/journal.pone.0139487

11. Strazza L, Azevedo RS, Carvalho HB, Massad E. The vulnerability of Brazilian female prisoners to HIV infection.
Braz J Med Biol Res. 2004;37:771-6. http://dx.doi.org/10.1590/ S0100-879X2004000500020

12. Berra JAP, Bacetti LB, Buzo AA. Seroprevalence of HIV, syphilis, and hepatites $\mathrm{B}$ and $\mathrm{C}$ among women confined at Centro de Ressocialização Feminino of Rio Claro, São Paulo. Revista di Instituto Adolfo Lutz (Impresso). 2006;65:133-6.

13. Barbour V, Clark J, Jones S, Veitch E; PLoS Medicine Editors. The health crisis of tuberculosis in prisons extends beyond the prison walls. PLoS Med. 2010;7:e1000383. http://dx.doi.org/ 10.1371/journal.pmed.1000383

14. Legrand J, Sanchez A, Le Pont F, Camacho L, Larouze B. Modeling the impact of tuberculosis control strategies in highly endemic overcrowded prisons. PLoS One. 2008:3:e2100. http://dx.doi.org/10.1371/journal.pone.0002100

15. Ribeiro Macedo L, Reis-Santos B, Riley LW, Maciel EL. Treatment outcomes of tuberculosis patients in Brazilian prisons: a polytomous regression analysis. Int J Tuberc Lung Dis. 2013;17:1427-34. http://dx.doi.org/10.5588/ijtld.12.0918

16. Urrego J, Ko AI, da Silva Santos Carbone A, Paião DS, Sgarbi RV, Yeckel CW, et al. The impact of ventilation and early diagnosis on tuberculosis transmission in Brazilian prisons. Am J Trop Med Hyg. 2015;93:739-46. http://dx.doi.org/10.4269/ ajtmh.15-0166

Address for correspondence: Jason R. Andrews, Stanford University, Division of Infectious Diseases and Geographic Medicine, 300 Pasteur Dr, Lane 141, Stanford, CA 94305, USA; email: jandr@stanford.edu

\section{etymologia}

\section{Mycobacterium chimaera [mi"ko-bak-tēr'e-əm ki-mēr'ə]}

\section{Ronnie Henry}

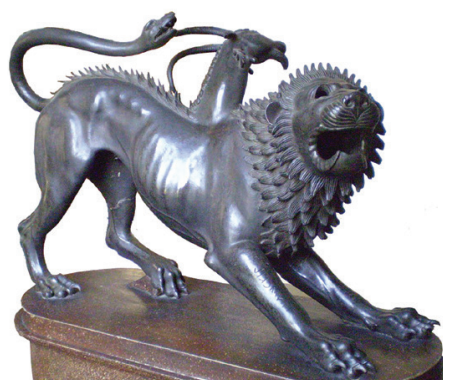

Etruscan bronze statue depicting the legendary monster, the chimera. National Archaeological Museum, Florence. Photograph by Lucarelli Museum, Florence. Photo
(Wikimedia Commons)
Gormerly an unnamed Mycobacterium sequevar within the M. avium- M. intracellulare-M. scrofulaceum group (MAIS), M. chimaera is an emerging opportunistic pathogen that can cause infections of heart valve prostheses, vascular grafts, and disseminated infections after open-heart surgery. Heater-cooler units used to regulate blood temperature during cardiopulmonary bypass have been implicated, although most isolates are respiratory. In 2004, Tortoli et al. proposed the name M. chimaera for strains that a reverse hybridization-based line probe assay suggested belonged to MAIS but were different from M. avium, M. intracellulare, or M. scrofulaceum. The new species name comes from the chimera, a mythological being made up of parts of 3 different animals.

\section{Sources}

1. Schreiber PW, Kuster SP, Hasse B, Bayard C, Rüegg C, Kohler P, et al. Reemergence of Mycobacterium chimaera in heater-cooler units despite intensified cleaning and disinfection protocol. Emerg Infect Dis. 2016;22:1830-3. http://dx.doi. org/10.3201/eid2210.160925

2. Struelens MJ, Plachouras D. Mycobacterium chimaera infections associated with heater-cooler units (HCU): closing another loophole in patient safety. Euro Surveill. 2016;21:1-3. http://dx.doi.org/ 10.2807/1560-7917.ES.2016.21.46.30397

3 Tortoli E, Rindi L, Garcia MJ, Chiaradonna P, Dei R, Garzelli C, et al. Proposal to elevate the genetic variant MAC-A, included in the Mycobacterium avium complex, to species rank as Mycobacterium chimaera sp. nov. Int J Syst Evol Microbiol. 2004;54:1277-85. http://dx.doi.org/10.1099/ijs.0.02777-0

Address for correspondence: Ronnie Henry, Centers for Disease Control and Prevention, 1600 Clifton Rd NE, Mailstop E03, Atlanta, GA 30329-4027, USA; email: boq3@cdc.gov

DOI: http://dx.doi.org/10.3201/eid2303.ET2303 